\title{
SOBRE 0 COMPORTAMENTO DE CHIMPANZÉS: O QUE ANTROPÓLOGOS E PRIMATÓLOGOS PODEM ENSINAR SOBRE $O$ ASSUNTO?
}

\author{
Eliane Sebeika Rapchan \\ Universidade Estadual de Maringá - Brasil
}

Resumo: Este artigo é um exercício etnográfico sobre a produção dos pesquisadores dedicados ao comportamento de chimpanzés enfocando questões relativas aos temas simbolização, sociabilidade, comunicação, cognição e consciência tomando o problema da existência de "culturas de chimpanzés", tal como muitos primatólogos têm afirmado na última década, como central. A estratégia consiste em estabelecer um diálogo constante entre a produção de conhecimento dirigida ao comportamento dos chimpanzés, a partir de 1960, e os próprios parâmetros e questões que a antropologia sociocultural enfatiza em sua reflexão sobre humanos, suas culturas, suas sociedades, via o debate entre local e universal, entre natureza e cultura. Os parâmetros teóricometodológicos utilizados são provenientes da antropologia da ciência, das ideias e do conhecimento, como é conhecida a área da antropologia dedicada a pensar aspectos da produção do conhecimento, dentro e fora da disciplina.

Palavras-chave: antropologia do conhecimento, capacidade simbólica, culturas de chimpanzés, relações natureza-cultura.

\begin{abstract}
This article is an ethnographic study about the researches dedicated to chimpanzee behavior focusing questions related to symbolization, sociability, communication, cognition and consciousness taking as central the problem of "chimpanzee cultures", as many primatologists have affirming to exist in last decade. The strategy consists in to establish a constant dialogue between the production of knowledge about the chimpanzee behavior, since 1960, and the parameters and questions that sociocultural anthropology emphasizes in its reflection about humans, theirs cultures, theirs societies, through the debate between local and universal, culture and nature. The theoretical and methodological parameters utilized coming from the Anthropology of Science, Ideas and Knowledge, as is named the anthropological area that think about aspects of production of knowledge, inside and outside the discipline.
\end{abstract}

Keywords: anthropology of knowledge, chimpanzee cultures, culture-nature relations, symbolic capacity.

Horizontes Antropológicos, Porto Alegre, ano 16, n. 33, p. 227-266, jan./jun. 2010 


\section{Antropologia sociocultural, antropologia da ciência e primatologia contemporânea}

Os parâmetros contemporâneos da teoria produzida pela antropologia sociocultural remontam à ruptura, entre o final do século XIX e início do século XX, com as tendências que pretendiam estabelecer relações diretas entre os fenômenos relacionados à cultura ou à sociedade e as concepções de evolução em suas várias vertentes, desde aquelas que pressupunham uma história universal válida para toda a humanidade (Stocking, 1982), na qual as diferenças étnicas e culturas estavam associadas a hierarquias nas capacidades humanas (Browne, 2007), até aquelas que preconizavam a eugenia (Browne, 2007).

Vários fatores estão associados a essa ruptura. Há um, no entanto, que, por ser essencial para esta discussão, exige atenção e reflexão. Ele corresponde às relações entre método e teoria, mais especificamente, entre etnografia e teoria antropológica. Isso porque, em essência, no momento em que os antropólogos passaram a fazer trabalhos de campo prolongados e sistemáticos (Boas, 1940; Malinowski, 1978), que resultaram em etnografias, o Ocidente começou a dispor de elementos para construir novas concepções de universalidade humana pautadas na reunião de expressões específicas de cada cultura e não mais na avaliação etnocêntrica de qualquer grupo a partir de si (Todorov, 1993). Surgiam, então, tipos completamente novos de alteridade. Isso porque fazer etnografia consiste em estabelecer contatos os mais intensos possível com a vida do grupo estudado para a coleta de dados, naquilo que Malinowski (1978) chamou de "pesquisa participante". O material coletado através de tal método tornou-se também a fonte privilegiada para a teoria antropológica.

Assim, a etnografia, ao mesmo tempo em que viabilizou o que chamamos de antropologia sociocultural moderna, produziu um paradoxo, que é uma forma de conhecimento cuja pretensão original era tratar do humano numa perspectiva universal e que se tornou viável a partir do estudo da particularidade, de cada população humana em sua especificidade (Lévi-Strauss, 1986).

Desse modo, ao repudiar, sob qualquer aspecto, a perspectiva evolucionista, a antropologia sociocultural afastou-se gradativamente dos chamados "grandes divisores" (Goldman; Lima, 1999), mas, ao mesmo tempo, continuou a problematizar as complexas relações entre o geral e o específico por meio do estruturalismo (Lévi-Strauss, 1988, 1989a, 1989b), da antropologia econômica ou materialista (Harris, 2008; Sahlins, 2005). Nas últimas décadas, iniciativas tais como as de Roy Wagner na década de 1970 e Adam Kuper

Horizontes Antropológicos, Porto Alegre, ano 16, n. 33, p. 227-266, jan./jun. 2010 
em 1990, via propostas de redimensionamento e reflexão sobre a noção de cultura (Kuper, 1999; Wagner, 1991), recolocaram o problema das referências universalistas para a antropologia. Posteriormente, Marilyn Strathern (1992) chamou a atenção para a necessidade de uma revisão sobre as concepções antropológicas e sociológicas de sociedade e sociabilidade e, por fim, mais recentemente, Bruno Latour (1991), tem proposto um redimensionamento da própria antropologia, através da chamada antropologia simétrica, que pretende lidar com dimensões-chave de nossa sociedade, como a ciência e a política, a partir do mesmo grau de sofisticação etnográfica que costumamos dedicar aos estudos dos saberes e técnicas em outra cultura, atribuindo às nossas instituições os mesmos status que atribuímos às de outras sociedades e revendo, inclusive, como tem feito também Tim Ingold (1996), as relações entre natureza e cultura ressaltando, aliás, que se não há cultura "em si", o mesmo vale para as concepções de "natureza".

Esse movimento recente que levou a antropologia sociocultural a pensar suas práticas, inclusive no que se refere às concepções de natureza, oferece recursos e perspectivas para se pensar sobre um fenômeno que retoma, e renova, questões e debates relativos ao momento de cisão entre a antropologia sociocultural e as biociências a partir de um problema específico. Desde a década de 1960, a produção dos pesquisadores dedicados ao estudo do comportamento de grandes símios, particularmente os chimpanzés, nossos parentes mais próximos (Fouts; Mills, 1998), os tem levado a afirmar, para espanto e surpresa de muitos cientistas sociais, que diferentes grupos de chimpanzés possuem "culturas" (McGrew, 2004; Wrangham et al., 2001; Whiten et al., 1999), reproduzem "tradições" (Nishida, 1987), lutam por "poder" (De Waal, 2000) e têm um tipo de inteligência cujo desenvolvimento é profundamente dependente de sua vida em grupo (Dunbar, 1997).

Este texto visa apresentar os resultados obtidos a partir de pesquisa realizada sobre o material produzido pelos primatólogos e suas ideias a partir das perspectivas oferecidas pela antropologia sociocultural sob a ótica da antropologia da ciência, das ideias e do conhecimento.

\section{Evolução, antropologia cultural e comportamento de grandes símios}

A ideia de evolução, tal como se manifestou na antropologia nas décadas definidas entre o final do século XIX e início do século XX (Blanc, 1975), 
implicou o repasse das explicações oferecidas à natureza aos fenômenos sociais e constituiu, talvez, o único paradigma integralmente descartado pela antropologia contemporânea. Antropólogos como Boas (Cf. Lewis, 2001) e Malinowski (1978), através, e a partir, da adoção e defesa do método etnográfico, promoveram combate eficiente ao darwinismo social e ao evolucionismo cultural que haviam atraído Spencer, Tylor, Morgan e outros (Stocking, 1982) em sua projeção de ideias de Darwin sobre as diferenças existentes entre povos, etnias e culturas (Browne, 2007; Stocking, 1982).

Nos últimos 50 anos, uma significativa gama de abordagens e disciplinas tem, por assim dizer, "provocado" os cientistas sociais em seu exercício de produção de conhecimento e no tratamento dos fenômenos, até agora, considerados exclusivamente humanos, produtos engendrados pelas relações humanas em toda sua extensão e, justamente por isso, objetos, por excelência, das chamadas humanidades. Mas o que uma observação mais cuidadosa dessa configuração pode revelar?

Por um lado, revela a ânsia das biociências de ampliar os limites e a aplicabilidade de suas explicações, buscando a legitimidade em produzir interpretações sobre, por assim dizer, um dos seres vivos mais complexos, o humano. Por outro, expressa o consenso, dentro e fora das ciências sociais, acerca da centralidade das relações sociais e das relações dos humanos com seu meio, como fatores essenciais na produção da inteligência, no desenvolvimento da cognição e da habilidade no convívio grupal. Daí fenômenos como cultura e sociedade terem se tornado algo que não pode ser desprezado, mesmo nas biociências, sendo consideradas, por muitos, como fatores evolutivos e adaptativos centrais e inerentes à espécie (Barkow et al. 1995; Cavalli-Sforza, 2001; Damásio, 2000, Hrdy, 2001; Kuper, 1994).

Por fim, coloca em conflito os pressupostos das ciências sociais e das biociências na medida em que estendem as características do corpo biológico ao comportamento, fornecendo explicações sobre a consciência, o comportamento, a centralidade da experiência coletiva e da cultura a partir do estabelecimento de inter-relações entre características anatomofisiológicas, evolutivo-adaptativas, genéticas, próprias da espécie e/ou partilhadas com nossos "parentes", grandes símios, outros mamíferos, etc. e o meio sociocultural, onde essas características afloram, desenvolvem-se e reinventam-se (Tooby; Cosmides, 1995), seja no plano individual ou no coletivo (Henrich; McElreath, 2003). 
Em contrapartida, observa-se que as concepções de humanidade, o relativismo cultural e a sensibilidade quanto às repercussões éticas e políticas das abordagens antropológicas influenciaram as biociências e sua história, suas descobertas e abordagens frequentemente consideram a necessidade de lembrar o quanto argumentos fundados na biologia deram sustentação a discursos e ações orientados pelo racismo, pelo etnocentrismo, pelo chauvinismo ou pela xenofobia (Browne, 2007; Cavalli-Sforza, 2001; Corbey; Theunissen, 1995; Hrdy, 2001; Wrangham; Peterson, 2004).

Já no âmbito das ciências sociais, particularmente na antropologia, devese considerar a potencial turbulência produzida pelos resultados das pesquisas sobre grandes símios, que, no mínimo, têm se constituído em temas "bons para pensar" (Rapchan, 2005). Os fenômenos registrados, o tipo de relação estabelecida entre pesquisadores e grandes símios (Jahme, 2001; Lestel, 2004), o uso de expressões próprias das ciências sociais para definir o comportamento de primatas ou, ainda, as repercussões das questões postas por antropólogos biólogos, etólogos ou psicólogos evolucionistas (Barkow et al., 1995) sobre o próprio modo de fazer antropologia e seus pressupostos são temas que merecem atenção. Há, ainda, que se considerar as influências, veladas ou explícitas, das ciências sociais sobre a primatologia, particularmente até os anos de 1960-1970, momento do início da carreira de muitos influentes primatólogos como Jane Goodall, Frans de Waal, Irwing De Vore, Toshisada Nishida e outros, alguns anos antes de a sociobiologia penetrar nas práticas da disciplina (Dukelow, 1999) e influenciar o ponto de vista dos primatólogos mais jovens.

Quanto ao método e à adoção de procedimentos de pesquisa, é possível encontrar, de modo mais marcante entre os primatólogos da geração de 19601970, influências advindas da antropologia sociocultural, particularmente no que se refere à adoção do trabalho de campo (contínuo, prolongado, minucioso) (Goodall, 1986) e a adoção de um tipo de registro que lembra o etnográfico, pois dá nome aos primatas, tem caráter descritivo-narrativo e estabelece constantemente comparações entre o grupo estudado e outros grupos e outras espécies, inclusive os humanos. A pesquisa pioneira do antropólogo social Irwing De Vore sobre a organização e vida coletiva dos babuínos africanos, registrada por Kuper em (1994) em The chosen primate, e a significativa influência de Jane Goodall, a partir de seus trabalhos fundados em observação e, ao menos no início, interação contínuas e prolongadas com chimpanzés em habitats africanos são alguns exemplos. Ao mesmo tempo, etólogos têm pensado 
sobre problemas, riscos e vantagens da antropomorfização do comportamento dos chimpanzés e sobre os procedimentos mais adequados para coleta de dados (Mitchell; Hamm, 1997). Dominique Lestel (2004), por exemplo, tem refletido sobre a intimidade criada entre pesquisadores e chimpanzés ou bonobos, que vivem em ambientes completamente humanizados, nas pesquisas dedicadas ao ensino de linguagem de sinais e à cognição. Ele os pensa como "animais especiais" que estabelecem "relações especiais" com os humanos. Segundo Lestel, dadas as condições de vida e interação desses animais, é impossível saber se eles são expressões fiéis de sua espécie. Por outro lado, têm surgido cada vez mais reflexões sobre as influências das projeções simbólicas de culturas acerca de primatas não humanos, na Europa (Corbey; Theunissen, 1995), no Japão (Asquith, 1995) e na África (Richards, 1995), sobre produções artísticas e intelectuais bem como sobre posições políticas acerca, por exemplo, de ações conservacionistas.

Diante dessa confluência de elementos, o debate sobre a noção das "culturas de chimpanzé" emerge de maneira insinuante. O crescente uso da noção de cultura fora dos terrenos da antropologia social e da antropologia cultural em pesquisas sobre o comportamento de várias espécies como cetáceos e algumas aves, mas particularmente no que se refere ao comportamento de chimpanzés, constitui-se no elemento central deste artigo. Isso não só porque o tema tem mobilizado significativa parcela dos mais importantes primatólogos da atualidade, dedicados aos estudos de comportamento, em favor da reunião de esforços para definir os termos de suas pesquisas, trocar dados, sistematizar as observações e alcançar denominadores comuns. Um dos resultados desse processo é verificável na realização de dois congressos internacionais em 1986 e 1991, denominados "Understanding chimpanzees" sobre comportamento de chimpanzés e patrocinados pela Academia de Ciências de Chicago, que resultaram na publicação da impactante coletânea Chimpanzee cultures (Wrangham et al., 2001) (ver também Whiten et. al., 1999), mas pode ser observado, também, no surgimento recente de inúmeros centros, núcleos e grupos de pesquisa dedicados ao assunto. Uma rápida pesquisa na internet pode revelar isso facilmente a qualquer que tenha curiosidade.

O potencial impacto disso tudo sobre as ciências sociais e as concepções que temos a respeito dos grandes símios e sobre nossas representações científicas, simbólicas e culturais acerca da natureza é imenso. Tudo isso sem falar na urgente necessidade de rediscutir as relações natureza/cultura, a partir 
de parâmetros que não se reduzam às concepções exclusivas da antropologia (Ingold, 1996). Desse modo, parece urgente avaliar os usos e sentidos da noção de cultura por parte dos pesquisadores do comportamento de chimpanzés. É preciso perguntar se essa noção opera nos termos adotados pela antropologia sociocultural ou se segue lógicas totalmente próprias e distintas; se a noção é totalmente singular à etologia e à primatologia e, então, trata-se de ideias independentes que, na prática, apenas adotaram o mesmo nome para diferentes concepções (Kuper, 1996). Ou seja, "cultura" no sentido da antropologia sociocultural e "cultura" no sentido da primatologia não têm muita coisa em comum, exceto o próprio nome. Caso contrário, essa noção diz respeito às práticas dos antropólogos sociais e culturais e, nessa condição, a antropologia deve manifestar-se sobre o assunto. A partir dessa etapa, colocam-se novos problemas.

Pensando a questão, trata-se amiúde, do ponto de vista dos primatólogos, de subsidiar a aplicabilidade do uso das mesmas noções, tais como "cultura" ou "tradição" para explicar aspectos do comportamento não só dos chimpanzés, mas de outros primatas, humanos incluídos, pela via comparativa, construindo pontes acerca das semelhanças entre seres que possuem grande proximidade genética e que podem, talvez, manifestar também semelhanças em certos âmbitos do comportamento (Pavelka, 2002).

A perspectiva de que "cultura" e "tradição" são fenômenos evolutivoadaptativos implica que a comprovação de sua existência entre, por exemplo, chimpanzés e a constituição de um consenso acerca disso levam à comprovação de que não apenas existe semelhança entre aspectos anatômicos e fisiológicos quando se trata de espécies geneticamente semelhantes, como é o caso dos humanos e dos chimpanzés, mas também há semelhanças entre fenômenos comportamentais complexos como cognição e inteligência, vida em grupo e sua dinâmica, por exemplo.

Ao mesmo tempo, se houver a possibilidade de os primatólogos conseguirem apresentar convincentemente seus argumentos em favor da existência de uma cultura de chimpanzés, uma das consequências para os antropólogos sociais e culturais seria a necessidade de repensar os parâmetros, limites e características daquilo que chamamos "alteridade" e mesmo do que entendemos por "humano" (Rapchan, 2002). Por outro lado, à medida que se descobre que os chimpanzés são muito mais semelhantes aos humanos do que jamais se concebeu ou admitiu, mesmo que a ideia de "culturas de chimpanzés" venha, 
porventura, a ser descartada, as contribuições dos antropólogos socioculturais para as pesquisas comportamentais da primatologia tornam-se indispensáveis, dado todo o conhecimento acumulado no âmbito das pesquisas de campo e da produção de etnografias (Tuttle, 2001), bem como de seu extenso arcabouço analítico e teórico desenvolvido para pensar tanto os sistemas de significado quanto os sistemas sociais (Oliveira, 1997).

\section{Culturas de chimpanzés}

No momento em que grupos de chimpanzés passaram a ser identificados como grupos sociais, foi possível analisar as interações que estabelecem entre si pelas chaves da aliança e do conflito, observando a importância do status e das vantagens adquiridas por cada chimpanzé no interior de seu grupo, bem como os ganhos advindos de suas capacidades de dissimular diante dos mais fortes, o potencial para reagir diante do inesperado e a transmissão de conhecimento adquirido aos mais jovens, mediados pelo que os pesquisadores têm chamado de "tradição" (Nishida, 1987).

A observação sistemática e prolongada do comportamento de cada grupo, associada a análises comparativas, possibilitou aos pesquisadores a identificação de padrões de comportamento próprios a cada população de chimpanzés (Whiten et al., 1999; Wrangham et al., 2001). As comparações possibilitaram, ainda, a definição de variações, padrões e permanências, de grupo a grupo, com relação a fenômenos tais como a catação (grooming), que é essencial para as interações sociais e é modulada para cada tipo de situação e posição no interior do grupo (Dunbar, 1997), as capacidades cognitivas e comunicativas (King, 2004, Tomasello, 2003), as motivações para os conflitos e para os mecanismos de apaziguamento (De Waal, 2007), o cuidado parental (Hrdy, 2001), as práticas de forrageio (Nishida; Ohigashi; Koshimizu, 2000), as estratégias de reprodução (Hrdy, 2001), as expressões corporais como formas de comunicação, a produção e o uso de ferramentas (Boesch; Boesch, 1990; McGrew, 1996), as relações entre fêmeas, filhotes, irmãos e o resto do grupo (Goodall, 1986; Hrdy, 2001), a dinâmica e os mecanismos de produção de status e hierarquia (De Waal, 2007, Goodall, 1986).

Essas "tradições" comportamentais, ontogeneticamente adquiridas, são repassadas no interior do mesmo grupo, de geração a geração, e caracterizam-se 
pela variabilidade e pela pluralidade (Whiten et al., 1999; Wrangham et al., 2001). Ou seja, variam de população a população e são plurais com relação ao mesmo quesito. Por exemplo, as posturas corporais adotadas no grooming ou as ferramentas utilizadas para "pescar" cupins de um grupo não são idênticas, se comparadas a outros. Além disso, quando se trata de chimpanzés que vivem em seus habitats originais, os pesquisadores têm tomado o cuidado de verificar se os comportamentos não foram adquiridos de seres humanos.

Apesar de existirem debates com relação à importância das pressões do meio sobre a dinâmica dos comportamentos (Galef, 1992), a importância da descoberta é inegável e o passo seguinte tem sido investigar os mecanismos acionados na transmissão de comportamentos complexos, o que implica observar os processos cognitivos, a capacidade de imitação (Tomasello, 2003), a facilitação aos filhotes pela mãe na observação de algumas de suas condutas (Boesch; Tomasello, 1998) e a existência, ou não, de uma "pedagogia dos chimpanzés". Os indícios levantados até o momento favorecem a identificação da existência dos três primeiros, mas há sérias dúvidas com relação à existência de aprendizado e atitude intencional de ensinar (Boesch; Boesch, 1990). Ou seja, provavelmente, cada pequeno chimpanzé "reinventa a roda", pulando algumas etapas graças ao que pôde observar com os mais velhos.

A reunião e a abordagem comparativa do material recolhido referente ao comportamento de diferentes grupos de chimpanzés levou um conjunto de alguns dos maiores estudiosos do assunto a afirmarem a existência de "culturas de chimpanzés", devido à identificação dos fenômenos relacionados à aquisição, à variabilidade e à transmissão de comportamentos duráveis e generalizáveis em populações distintas. Um dos resultados dessa reunião, já mencionado anteriormente, é a tomada pública e coletiva da defesa da existência de "culturas de chimpanzés" (chimpanzee cultures) por esses pesquisadores (Whiten et al., 1999; Wrangham et al., 2001). O diálogo entre eles tem promovido, por sua vez, o desenvolvimento de estudos comparativos (Heltne, 2001: xi) e a padronização dos procedimentos de campo (Goodall, 2001, p. xix), mas, principalmente, tem levado os pesquisadores a adotar termos e noções que, até algumas décadas, eram exclusivamente dirigidos a fenômenos humanos.

Nesse sentido, saltam aos olhos de qualquer cientista social os temas abordados pelos pesquisadores do comportamento de chimpanzés em livros e artigos recentes, que podem ser classificados em dois grupos. No primeiro encontram-se trabalhos sobre relações mãe/filhote (Hrdy, 2001), 
reconhecimento visual entre mãe e filhote (Parr; De Waal, 1999) e infanticídio (Arcadi; Wrangham, 1999; Hrdy, 2001); conflito social (Arnold; Whiten, 2001; Baker; Smuts 2001; Baker et. al, 2000; Boehm, 2001; Mason; Mendoza, 1993); uso de ferramentas, fabricação de ferramentas e fabricação de ferramentas para produzir outras ferramentas (Boesch; Boesch, 1990; Matsuzawa, 2001; McGrew, 1996); reciprocidade nas relações grupais (Brosnan; De Waal, 2003), agressividade (Wrangham; Peterson, 2004), relações entre variabilidade cultural e tradição (Nishida 1987; Tomasello, 2003; Wrangham et al., 2001) e diversidade intergrupal no uso de plantas medicinais, entre outros.

No segundo grupo é possível encontrar trabalhos voltados para registrar e analisar a diversidade manifesta em interações no interior dos grupos de chimpanzés (Baker; Smuts, 2001; De Waal, 2007; McGrew, 2004; Stanford, 1998); os fenômenos classificados pelos primatólogos como "cultura" e a decorrente variabilidade cultural (Tomasello, 2003; Whiten et al., 1999; Wrangham, 2001), tradições sociais, transmissão cultural e seus mecanismos (Bonner, 1983; Nishida, 1987; Tomasello, 2003; Wrangham et. al., 2001); cultura material e uso de ferramentas (McGrew, 1996); poder (De Waal, 2000); percepção do mundo (Cheney; Seyfarth, 1990), cognição e entendimento (De Waal, 2001b; Hooff, 2001; Joulian, 1996; Tomasello; Call, 1997), potencial adaptativo (De Waal, 2001a), linguagem, comunicação e inteligência (Fouts; Mills, 1998; Parker; Gibson, 1994; Rumbaugh; Savage-Rumbaugh; Sevcick, 2001; Wolker, 1995).

Preocupados em observar, registrar e analisar o comportamento de chimpanzés tendo a proximidade genética entre humanos e primatas superiores como pano de fundo, mas enfatizando os aspectos observáveis da conduta, nesses trabalhos, particularmente os desenvolvidos na África, muitos primatólogos agregaram, além de seus coordenadores, inúmeros outros coletores de dados, desde membros treinados da população nativa a estudantes de pós-graduação. Essas equipes ocupam-se em observar e registrar aspectos relacionados ao desenvolvimento dos filhotes em relação às suas mães e os vínculos entre ambos, o comportamento e estratégias sexuais, os conflitos e sua resolução, a importância do grupo, o comportamento com relação ao sexo, a produção e utilização de objetos, os mecanismos de comunicação, a constituição de hierarquias e status, a resolução de problemas, a dissimulação e o repasse de informação.

A maior parte desses trabalhos, apesar de orientados por procedimentos da sociobiologia e da ecologia comportamental evolutiva (Dukelow, 1999), 
enfoca o comportamento dos chimpanzés a partir de seu meio ecológico e das interações no interior de um grupo e, por isso, a adoção de explicações com fundamentos evolutivo-adaptativos dá-se, geralmente, a posteriori, subordinada aos dados de campo. E não poderia ser de outro modo: quanto mais as investigações avançam, mais os pesquisadores percebem a importância da experiência na configuração do comportamento destes grandes símios, a ponto de existir variabilidade de grupo a grupo, padrões seguidos no interior do mesmo grupo e permanência de comportamentos próprios de determinado grupo ao longo de gerações. Isso levou os primatólogos a afirmarem que o que existem são culturas de chimpanzés, no plural, e não cultura de chimpanzés, o que faz sentido, caso contrário tratar-se-ia, quase que certamente, de comportamento ditado por herança genética, um contrassenso diante dos rumos seguidos pela primatologia contemporânea.

A consequência disso, que se pode perceber em inúmeros trabalhos cujo foco é o comportamento animal, e a análise aqui será apenas voltada aos trabalhos dirigidos aos grandes símios (Brosnan; De Waal, 2003; De Waal, 2001a, 2001b; Goodall, 2000; Hrdy, 2001; McGrew, 1996, 2004; Nishida, 1987; Rumbaugh; Savage-Rumbaugh; Sevcick, 2001; Tomasello, 2003; Whiten et al., 1999; Wrangham et al., 2001; Wrangham; Peterson, 2004), é a ênfase em abordagens "abertas", interativas e muito distantes de concepções pautadas em determinações genéticas manifestas através do que é correntemente chamado de "inato".

Contudo, a afirmação da existência de culturas de chimpanzés coloca dois grandes conjuntos de questões. $\mathrm{O}$ primeiro, associado à antropologia sociocultural, remete à ideia de totalidade da cultura e à centralidade de sua dimensão simbólica (Rapchan; Neves, 2005). A ideia de totalidade é um princípio da antropologia social, proposto por Marcel Mauss (2007), segundo o qual as dimensões materiais, sociais e simbólicas associam-se de modo a constituir a cultura de um grupo humano. Cada uma dessas dimensões é constituída por muitas variáveis dinâmicas e é através do método etnográfico que o antropólogo penetra esse universo e consegue registrá-lo de um modo tal que aqueles que tiverem contato com a etnografia terão canais de acesso à cultura por ela registrada.

No caso das "culturas de chimpanzés", cada aspecto do comportamento é geralmente tratado isoladamente e não na sua relação com os outros, ou seja, costuma faltar nas abordagens análises relativas à interação entre diferentes 
aspectos do comportamento de um mesmo indivíduo ou do indivíduo sobre o grupo. Exceções à regra são as abordagens dos primatólogos da já mencionada geração de 1960-1970. Esta ausência dificulta, entre outras coisas, o acesso à verificação da existência de algum tipo de sentido nesses comportamentos, e esse é o outro aspecto importante da noção antropológica de cultura, pois ela é algo que fornece sentido à ação. O registro do comportamento é incompleto se não estiver associado aos seus próprios sentidos. Por isso a dimensão simbólica é central para a antropologia. Ela é o fundamento da produção de sentidos para qualquer sociedade humana.

O segundo conjunto de questões diz respeito às implicações evolutivas da ideia de cultura, ou seja, a paleoantropologia dedica-se intensamente a descobrir a partir de quando, ou de quem, é possível traçar as origens do que chamamos humano moderno (Mithen, 2002) e aí, evidentemente, a cultura, ou a capacidade simbólica, constituem-se nos pontos mais críticos.

Bipedia, capacidade manipulativa e tamanho do cérebro são indicadores anatômicos da proximidade entre grandes símios, hominíneos e humanos modernos. Com relação ao comportamento, a identificação de organização social complexa, como a encontrada entre humanos, deve estar associada a "uma criatividade ilimitada em todas as dimensões de nossa vida" (Neves, 2006, p. 274). Esses são os parâmetros mais comuns adotados pelos especialistas para avaliar material arqueológico e paleoantropológico disponíveis, no tocante à identificação de cultura.

Nesse sentido, a abordagem que melhor atende ao debate sobre a existência ou não de cultura entre os chimpanzés é a que dirige o foco para a capacidade simbólica, proposta por Steven Mithen (2002). Nos chimpanzés, os domínios da mente associados à engenhosidade técnica, organização e interação social, capacidade comunicativa e intensa exploração do meio são extremamente desenvolvidos, mas encontram-se isolados uns dos outros de um modo tal que é impossível deslocar uma informação de um módulo para outro. Aliás, provavelmente, a não identificação de uma "pedagogia" entre adultos e filhotes chimpanzés está diretamente relacionada à sua incapacidade de produção simbólica e abstração.

Por outro lado, o pleno domínio da capacidade simbólica existente nas mentes humanas permite a produção de sentidos complexos, a abstração e o deslocamento de informações de um domínio a outro. São os símbolos que permitem tais operações. Arte, ciência, instituições sociais, sistemas 
linguísticos complexos e religião são expressões dessa capacidade, e é aí que reside a cultura.

\section{A vida coletiva dos chimpanzés}

Segundo Wolfgang Köhler (1999), o importante psicólogo alemão ligado ao movimento de criação da Gestalt, um chimpanzé mantido em isolamento não é verdadeiramente um chimpanzé porque o comportamento de cada semelhante é um incentivo adequado para suscitar formas essenciais de seu comportamento. Tal observação aponta para o fato de que chimpanzés não nascem equipados com um conjunto preestabelecido de comportamentos adequados à sua existência e realização como um típico chimpanzé. E, mesmo que porventura exista um repertório inato de comportamentos possíveis, é preciso que um filhote chimpanzé observe seus semelhantes e interaja com eles a fim de aprender como e quando adotá-los. É isso que o tornará um chimpanzé, do ponto de vista de seu comportamento. Tudo isso é muito importante porque, de um lado, enfatiza o papel da vida coletiva na constituição do comportamento dos chimpanzés e descarta qualquer modelo mecanicista na definição de seu comportamento. De outro lado, indica que a cognição é algo importante para os chimpanzés e que eles possuem o que seja, talvez, uma cognição potencialmente complexa em sua forma mais primordial, ou seja, pautada em imitação, convivência, observação e interação.

Ao mesmo tempo, trabalhos desenvolvidos nas últimas quatro décadas sobre agrupamentos de chimpanzés em seus habitats originais têm revelado elementos importantes para a compreensão da vida coletiva desses grandes símios. Na década de 1960, Toshisada Nishida foi o primeiro pesquisador a defender a existência de uma natureza estável dos grupamentos de chimpanzés, que ficou conhecida como "comunidade" ou "unidade-grupo" (Nishida, 1968 apud Stanford, 1998, p. 399). Nishida pautou-se no modelo de "fusãofissão", já usado para descrever dinâmicas coletivas de outros primatas, para descrever a natureza fluida e temporária dos grupos de chimpanzés que observou em Mahale, África (Mitani, Watts; Muller, 2002, p. 10). Apesar de não haver registros da reunião de todos os membros de uma mesma comunidade num único tempo e lugar, Nishida verificou a existência de uma evidente rede social estruturada a partir das relações estabelecidas entre os indivíduos de um 
mesmo grupo (Mitani, Watts; Muller, 2002, p. 10), machos e fêmeas adultos e filhotes reunidos em grupos menores (parties) que variam em tamanho, composição e duração (Mitani, Watts; Muller, 2002, p. 10) em função da dinâmica do próprio grupo.

Dentre os vínculos "fortes" identificados entre os chimpanzés, há dois que se destacam. Aqueles estabelecidos entre machos adultos em sua luta para obter e manter o poder (De Waal, 2007) e os vínculos constituídos entre fêmeas e seus filhotes (Hrdy, 2001). Pesquisas realizadas sobre animais confinados e sobre animais que vivem em seus habitats nativos têm indicado que entre os chimpanzés os vínculos estabelecidos entre um filhote e sua mãe e entre os filhotes nascidos de uma mesma mãe não são apenas extremamente fortes, mas também bastante duradouros, estendendo-se por toda a vida, inclusive quando os filhotes tornam-se adultos. Segundo Goodall (1986), entre chimpanzés, os vínculos entre mães e filhotes são visivelmente os mais fortes e estáveis.

Entre uma fêmea chimpanzé e seu filhote, os vínculos envolvem inicialmente a extrema dependência do bebê em relação à mãe, que implica, inicialmente, proteção, alimentação, higiene, mas contempla também brincadeiras, companhia, aliança diante do grupo, partilha de alimentos e defesa mútua à medida que a prole cresce. Ou seja, estão relacionados à sobrevivência imediata mas também estão ligados ao desenvolvimento ontológico do filhote (Tomasello, 2003). Goodall observou, entre os chimpanzés de Gombe, que variações nos comportamentos das mães frente a seus filhotes têm repercussões sobre a constituição de seu comportamento e que o status das mães é repassado aos seus filhos. Há, também, muitos registros de brincadeiras e cuidados entre os filhotes de mesma mãe (Goodall, 1986). Considerando os intervalos de aproximadamente cinco anos entre cada gestação de chimpanzé, que geralmente produz um único bebê, o que ocorre é que o irmão ou irmã mais velhos já são completamente independentes, do ponto de vista da sobrevivência, quando nasce o caçula, e assim podem contribuir nos inúmeros cuidados com o frágil recém-nascido (Hrdy, 2001).

Os fortes vínculos entre machos chimpanzés, aparentados ou não, de uma mesma comunidade estão fundados na luta pelo poder, que está relacionado a ser o macho alfa ou um de seus aliados mais próximos (De Waal, 2007) e manifestam-se nas práticas de grooming, em coalizões fundadas em interesses ou conflitos, na constituição de grupos para caçar e partilhar carne e 
na formação de patrulhas para controlar as fronteiras de seu território (Mitani; Merriwether; Zhang, 2000).

Mitani, Watts e Muller (2002) apresentam um balanço rigoroso sobre as pesquisas relacionadas às práticas de caça coletiva do red colubus, um pequeno macaco que é a presa preferida de chimpanzés. Os chimpanzés são extremamente eficientes em caçá-lo, o que, diga-se de passagem, não é nada fácil. Essa prática foi identificada em várias populações de chimpanzés na África. Tal balanço foi orientado por duas questões centrais: quais fatores afetam a caça e quais fatores estão associados à partilha da carne resultante da empreitada com os semelhantes (Mitani; Watts; Muller, 2002, p. 16).

Por meio de tal exercício, foi possível apontar uma riquíssima lista de comportamentos associados a variantes ecológicas e contextos diversos, as variações de grupo a grupo e os aspectos mais gerais do comportamento associado às práticas de caça por chimpanzés. Através desse exercício, os autores identificaram, ainda, três eixos importantes na discussão: a caça coletiva associada à carência de outros alimentos, a caça associada ao comportamento sexual e a caça como ferramenta política.

No primeiro caso, partem do trabalho de Teleki (1973 apud Mitani; Watts; Muller, 2002, p. 16), desenvolvido em Ngogo (Parque Nacional de Kibale - Uganda) e tomado como referência por cerca de 25 anos. Segundo a autora, a prática da caça visaria suprir faltas nutricionais. Contudo, os pesquisadores contra-argumentam defendendo que dados mais recentes apontam que as maiores frequências de caça estão justamente associadas à abundância dos outros tipos de alimento.

No segundo caso, os autores partem da hipótese de Stanford (1998 apud Mitani; Watts; Muller, 2002, p. 16-17), provocativamente chamada de "carne por sexo" (meat-for-sex), segundo a qual machos iriam à caça para ofertar carne às fêmeas no estro em favor de relações sexuais. Apesar dos apelos estimulantes de tais possibilidades, associadas ao aumento das caçadas no período do estro das fêmeas chimpanzés de Gombe, sua comprovação não se sustenta porque, apesar de um maior número de caçadas estar relacionado ao estro das fêmeas em Gombe, o mesmo não se verifica em Ngogo, por exemplo. Contudo, dados levantados por McGrew (1992 apud Mitani; Watts; Muller, 2002, p. 16-17) indicam relações entre fecundação e ingestão de carne pelas fêmeas. 
No terceiro, Nishida e colegas (2001 apud Mitani; Watts; Muller, 2002, p. 17) apresentam a hipótese de que machos chimpanzés distribuem estrategicamente seu resultado de caça a fim de obter favores e apoio de outros membros do grupo, a partir de observações do grupo $\mathrm{M}$ de Mahale. Tais observações somam-se aos dados recolhidos por Mitani, Watts e Muller (2002, p. 17) em Ngogo. Os autores (Mitani, Watts; Muller, 2002, p. 17) sugerem que grupos maiores e maior número de caçadores estão associados à frequência das caçadas. Já Boesch (1996 apud Mitani, Watts; Muller, 2002, p. 17) supõe, via observações realizadas em Taï, que machos caçadores dividam seletivamente a carne obtida para garantir cooperação no interior do grupo. Contudo, isso tem sido difícil de comprovar devido às condições de observação da caça do red colubus que impedem, por exemplo, que os pesquisadores verifiquem os chimpanzés que participaram ativamente da caça mas não tiveram sucesso (bystanders) e os trapaceiros (cheaters).

Indo além, os autores enfatizam que o fato de os machos chimpanzés serem os atores predominantes das trocas nos grupos, indica que as trocas não são apenas seletivas mas também recíprocas, apontando para a existência de alianças que concorrem para a dinâmica de formação do status no interior do grupo, lembrando que altas posições sociais significam mais oportunidades sexuais para os machos.

Caso a hipótese se confirme, teremos aqui um filão para discussões futuras com as ciências sociais: a existência de relações entre cooperação grupal e a partilha de um recurso apreciado entre não humanos, o que lembra a reflexão sobre a dádiva de Marcel Mauss (1974) e a reflexão sobre a circulação de bens, palavras e mulheres de Lévi-Strauss (1988). De Waal (2007) especula que a predisposição à troca, à colaboração em um conjunto e à reciprocidade pode estar ligada à evolução da empatia. Segundo ele, o desenvolvimento da empatia tem provavelmente suas raízes nas fortíssimas relações mãe-filhote, muito importantes entre primatas. Formas mais elaboradas de empatia podem ter evoluído de formas mais primárias e básicas. A empatia é, de acordo com De Waal, indispensável no comportamento da mãe em favor da sobrevivência de seus filhotes e na cooperação. $O$ autor observa, ainda, que a empatia pode, inclusive, estar ligada a diferenças sexuais, dado que o autismo aparece com frequência muito maior entre os machos da espécie humana. 


\section{Sexo importa (e muito!)}

Ainda na década de 1960 passaram a circular, entre os primatólogos, concepções distintas acerca das formas de participação de machos e fêmeas nos grupos. Uma delas, a mais bem aceita, orientava-se pelo princípio de que os machos seriam filopátricos (philopatric), ou seja, permaneceriam por toda a vida no grupo em que nasceram, e que as fêmeas tenderiam à dispersão, deixariam seu grupo durante a adolescência, geralmente durante o estro, quando são muito atraentes e potencialmente muito bem aceitas, tornando-se assim membros de outros grupos (Mitani; Watts; Muller, 2002, p. 10).

Segundo essa perspectiva, apresentam-se dois conjuntos de elementos para discussão na relação entre sexo e dinâmica do grupo. O primeiro compreende a influência das diferenças entre sexos, o comportamento associado ao sexo e seus desdobramentos sobre a organização do grupo. O segundo implica a observação das relações entre parentes e não parentes (chimpanzés que possuem vínculos de sangue ou não), a partir da relação fundamental mãe-filhote.

Diferenças nas associações entre chimpanzés vinculadas ao sexo foram, aliás, de acordo com Mitani, Watts e Muller (2002, p. 10), observadas por Toshisada Nishida enquanto ele procurava levantar dados mais consistentes sobre suas proposições acerca da existência de comunidades de chimpanzés. Os mesmos autores observam que tanto Goodall (1986) quanto Nishida (1987) concordaram que machos chimpanzés são mais gregários e buscam mais constantemente a companhia uns dos outros, exceto nos períodos de acasalamento, quando convivem intensamente com as fêmeas. Estas, por sua vez, convivem mais intensamente com seus filhotes e tornam-se mais sociáveis durante o estro (Hrdy, 2001; Mitani, Watts; Muller, 2002, p. 10). Tais observações foram confirmadas por dados coletados em Gombe, em Mahale, no Parque Nacional Kibale (área de estudos Kanyawara) e Uganda.

Entretanto, dados mais recentes têm demonstrado que a permanência ou não no grupo de nascimento em função do sexo varia de grupo a grupo. Um fator relacionado à variância é o status da mãe no grupo, pois filhotes, machos ou fêmeas, nascidos de mães de alto status tendem a permanecer no grupo, enquanto que filhotes fêmeas nascidas de mães de baixo status saem do grupo, como relatado em Gombe por Goodall (1986). Outro fator relacionado ao não abandono do grupo de nascimento pela jovem fêmea é a não existência de outros grupos de chimpanzés partilhando fronteiras. 
Mais recentemente, os dados coletados por Frans De Waal (2007) fizeramno afirmar que enquanto as fêmeas chimpanzés esforçam-se por evitar conflitos, os machos são mais predispostos às turras. Em contrapartida, os machos adotam comportamentos para reatar as interações com muito mais frequência do que as fêmeas, que mantêm-se distantes dos membros do grupo com os quais houve enfrentamento. Segundo De Waal, isso está relacionado à participação dos machos nos grupos de poder que se modificam, reagrupam-se e, às vezes, exigem alianças entre inimigos. O conflito entre fêmeas, por sua vez, estabelece uma relação de desconfiança e afastamento, considerando, inclusive, que, quando tem um recém-nascido, a fêmea e seu pequeno bebê estão, sob certa perspectiva, numa situação de fragilidade e precisam garantir que estão cercados apenas por membros de confiança (Goodall, 1986; Hrdy, 2001).

\section{Antropologia da ciência, das ideias e do conhecimento}

A contribuição que, de fato, a antropologia pode trazer para o território das reflexões sobre conhecimentos, saberes e ideias pode ser expressa e contabilizada pela própria experiência, acumulada no interior da disciplina, através do exercício constante de coleta e análise de diversas formas de produção, preservação e reprodução de saberes e conhecimentos em sociedades tradicionais e não tradicionais, obedecendo métodos e princípios determinados, apesar de distintos, segundo escolas ou paradigmas.

Pode-se, em certa medida, afirmar que, desde sua origem, a antropologia, tout court, tem concentrado esforços no sentido de equacionar as maneiras pelas quais populações ou grupos específicos organizam seus símbolos, linguagem, sistemas classificatórios, descobertas, manifestações estéticas, reflexões e experiências acumuladas. De certo modo, mesmo os primeiros intelectuais devotados à antropologia, ainda bastante mergulhados nos princípios evolucionistas, esforçaram-se no sentido de efetuar os registros sobre linguagem, religião e parentesco que conseguiram obter, a partir de fontes secundárias ou observação direta, sobre populações que, originalmente, se constituíram enquanto alteridades frente aos intelectuais europeus.

Por exemplo, a produção antropológica francesa, a partir de trabalhos tão distintos quanto os de Marcel Mauss (1974), Claude Lévi-Strauss (1988, 1993), Louis Dumont (1993), Phillippe Descola (1994) e Dan Sperber (1996), 
trouxe grandes contribuições para a reflexão acerca das formas humanas de produção de saberes e conhecimentos, a partir de pesquisas sobre tais sociedades. Do mesmo modo, a antropologia britânica, através de autores como Bronislaw Malinowski (1978) e E. E. Evans-Pritchard (1978) ou a escola norte-americana de antropologia cultural, inaugurada por Franz Boas (1940) e desdobrada em vertentes distintas através dos trabalhos de Margareth Mead (1969), Ruth Benedict (1988; [s.d.]), Alfred Kröeber (1952) e outros, promoveu avanços, em vários sentidos, nessa área do conhecimento. As reflexões contemporâneas da escola interpretativista americana (Geertz, 1978) e seus desdobramentos, críticos ou concordantes, no próprio meio acadêmico americano (Marcus, 1995; Rabinow, 1983), mas também em outros meios (Carvalho, 1988), como o da antropologia social europeia (Kuper; Kuper, 2003; Strathern, 1992), têm procurado dar conta desse tipo de questão, a partir dos pontos de vista que adotam e das perspectivas que propõem a si.

A recondução dessa experiência acumulada pela antropologia em direção ao estudo específico das formas de produção de saberes e conhecimentos pode não só colocar procedimentos e técnicas desenvolvidos para fins de registros e coletas etnográficos à disposição, como pode, também, enfocar um ponto de vista peculiar e importante sobre seus produtores, de modo a deslocá-los e reintroduzi-los nas redes de relações culturais e de parentesco, dos grupos de poder e de afinidade, dos valores, regras, normas e padrões, rituais, símbolos e hierarquias.

Nesse sentido, os esforços recentes dos antropólogos, a fim de promover reflexões orientadas para o terreno específico da produção do conhecimento, no interior de áreas científicas e disciplinas, inclusive a sua própria, têm apresentado resultados relevantes em áreas distintas como a etnografia da ciência (Latour, 1991), a antropologia da antropologia (Oliveira, 1997; Peirano, 2006), a história da antropologia (Schwarcz, 1993; Stocking, 1982) ou a história das ideias (Goldman; Lima, 1999; Kuper, 1996), alguns exemplos das possibilidades latentes desse tipo de abordagem.

A antropologia da ciência, das ideias e do conhecimento (Holton; Elkana, 1997) surge na década de 1990 e traz um novo ponto de vista para várias questões relativas à ciência, epistemologia e tecnologia, produzindo reflexões sobre o uso de ideias "antropologizadas" como cultura e sobre a adoção do método etnográfico em campos e temas de pesquisa que não são classicamente antropológicos, tais como a primatologia e laboratórios. Tal iniciativa 
acrescentou uma perspectiva antropológica aos modos de se ver e pensar sobre certos aspectos de nosso mundo, e modificou nossa compreensão sobre certas áreas do conhecimento ao discutir temas como "materialidade", "hibridez" e "alteridade".

O trabalho pioneiro de Bruno Latour (1991) na década de 1970, uma pesquisa etnográfica em um renomado laboratório científico fazendo uso do rigor e das categorias antropológicas, desembocou numa proposta que ele chamou de "antropologia simétrica", ou seja, que os antropólogos tratem do mesmo modo, e com o mesmo rigor dirigido a outras populações, os objetos de estudo de nossa própria sociedade, especialmente a ciência e a política. Tal iniciativa promoveu uma guinada nas concepções estabelecidas acerca da ciência e dos temas tidos como tipicamente antropológicos. Partindo da concepção de que a ciência modifica nossos corpos, o mundo e a natureza, bem como as concepções que temos de cada um desses elementos, a antropologia da ciência propõe a realização de etnografias em laboratórios e trabalhos de campo nas áreas de atuação de outras disciplinas, como a primatologia. No nível teórico, pretende promover reflexões sobre as relações natureza-cultura nesses novos níveis.

De acordo com Haraway (1991), a construção discursiva que coloca a natureza como "Outro" é algo que nunca havia ocorrido antes, mas aconteceu no final do milênio. Sendo assim, tornou-se necessário estabelecer um outro tipo de relação com a natureza que esteja para além da reificação e da possessão (Haraway, 1991, p. 296). Ao mesmo tempo, ela ressalta que as relações de pesquisa dirigidas à natureza estabelecem com a sociedade relações de mão dupla. Haraway (1989) observa a importância central das representações acerca dos primatas sobre teoria e política nos EUA no século XX, ao mesmo tempo em que concepções de raça, gênero, interesses coloniais e pós-coloniais influenciaram e foram profundamente influenciados pela mesma primatologia.

Um exemplo forte de tal influência é apresentado pelo primatólogo Frans de Waal quando faz um retrospecto das relações entre certas ideias acerca dos genes e ideias circulantes na mídia, na política ou no cinema em uma mesma época. Observa, por exemplo, que a primeira cena de 2001 - uma odisseia no espaço de Stanley Kubric carrega a ideia de que a violência é benéfica do mesmo modo que a chamada hipótese "fora da África", segundo a qual chegamos a ser o que somos por meio de genocídios, o que se manifesta em livros com os sugestivos títulos Man the hunter (Homem, o caçador), O macho demoniaco, The imperial animal (O animal imperial) e The dark side of man (O lado 
sombrio do homem) (De Waal, 2007, p. 37), que apresentam o chimpanzé macho apenas como referência evolutiva dos homens violentos fixados em combates por sexo e na busca do poder e as fêmeas como beldades dos filmes de James Bond: razão dos embates entre machos, parceiras sexuais e só. Ou, ainda, na análise entre as ideias dos aliados Reagan e Tatcher e a concepção de "gene egoísta":

Na mesma época em que Ronald Reagan e Margaret Tatcher pregavam que a ganância era benéfica à sociedade, à economia e certamente àqueles com qualquer razão para serem gananciosos, biólogos publicaram livros que apoiavam tais idéias. O gene egoísta, de Richard Dawkins, ensinava que, como a evolução ajuda quem se ajuda, o egoísmo devia ser visto como uma força indutora de mudança, e não uma falha que nos arrasta ladeira abaixo. Podemos ser primatas perversos, mas isso é explicável e benéfico para o mundo. (De Waal, 2007, p. 35).

Assim, a adoção de uma perspectiva metodológica pautada na antropologia da ciência visa levantar e analisar a produção relacionada à cognição e à produção simbólica baseada em referenciais naturalísticos ou evolutivos nas últimas três décadas e publicada em livros ou nos mais importantes periódicos voltados ao assunto, principalmente os produzidos pela antropologia biológica e pela primatologia sob a perspectiva dos registros arqueológicos e dos dados etnográficos de culturas humanas modernas como, aliás, têm trabalhado Gibson e Ingold (1995).

O exercício analítico proposto pretende operar com alguns aspectos das reflexões teórico-metodológicas provenientes da antropologia das ideias e do conhecimento (Goldman; Lima, 1999; Holton; Elkana, 1997;Kuper, 1996; Latour, 1991; Oliveira, 1997; Stocking, 1982), como é conhecida a área da antropologia dedicada a pensar aspectos da produção do conhecimento, dentro e fora da disciplina, e foi o recurso metodológico utilizado aqui para analisar os usos e sentidos da noção de "culturas de chimpanzés", termo proposto e defendido por um número significativo de influentes primatólogos nas últimas duas décadas. Tal abordagem sustenta-se principalmente sobre a possibilidade de algumas reflexões contemporâneas das ciências sociais contribuírem, a partir de seus objetos, métodos e teorias, com o debate estabelecido em torno da produção de saberes e conhecimentos, a partir das iniciativas de sociólogos e a antropólogos em refletirem sobre o que é produzido por suas próprias disciplinas e por outras, que venham afetar-lhes diretamente, ou não. 
Uma das contribuições de Kuper nesse horizonte consistiu em observar que ideias produzidas no interior de uma disciplina podem deslocar-se para outra mantendo seu antigo nome e adquirindo novos sentidos e conteúdos. Ao mesmo tempo, outras ideias podem mudar de nome e continuar carregando os mesmos sentidos no interior da disciplina que as geraram. Kuper (1996) valeu-se das concepções lévi-straussianas sobre as relações de semelhança entre o pensamento mítico e o pensamento científico para equacionar estes mecanismos da produção de conhecimento e, assim, delineou uma poderosa ferramenta aplicável a esse tipo de problema, apesar de não tê-la ainda refinado.

A ideia de cultura, do modo como tem sido utilizada no âmbito do comportamento de chimpanzés, certamente presta-se a análises orientadas pelas perspectivas supramencionadas pois transforma-se, ao ser deslocada da antropologia sociocultural para disciplinas orientadas por fundamentos das biociências. Ao mesmo tempo, há um elenco de sentidos associados à ideia de cultura que se tornaram alvo de disputa para pesquisadores pertencentes a áreas externas às ciências sociais.

Desde a crítica ao evolucionismo social e ao darwinismo cultural produzida por Boas, que se estabeleceu definitivamente no pós-guerra e vigorou até o período entre 1960 e 1970 (Weiner, 2001), era consenso em todo o meio científico, dentro e fora das ciências sociais, que o comportamento humano possuía características exclusivas e só poderia ser satisfatoriamente explicado pelas ciências sociais. Entretanto, isso tem mudado nos últimos 50 anos, e tanto pesquisadores orientados pelas biociências reivindicam o direito de explorar os fenômenos socioculturais quanto estudiosos dedicados ao comportamento de seres não humanos proclamam a existência de formas não humanas de comportamento, típicas em outras espécies, adquiridas pela experiência, pelo contato de filhotes com adultos e pela participação em grupos caracterizados por intensas interações.

\section{Capacidade simbólica, cognição e sociabilidade}

Segundo Mitani, Watts e Muller (2002), vários pesquisadores têm observado que a diversidade de comportamentos coletivos de machos e fêmeas está associada à adoção de estratégias diversas para acasalamento e aos custos na obtenção de alimentos e, nesse sentido, pressões do meio, recursos 
disponíveis, tamanho e grau de isolamento do grupo são fatores a serem considerados nas análises. Mas eles observam também a existência de outras dificuldades que, quando analisadas da perspectiva das ciências sociais, podem estimular reflexões relevantes para o debate. Isso porque os pesquisadores dedicados à vida coletiva dos chimpanzés têm se deparado com dilemas tipicamente sociológicos e antropológicos.

Ou seja, tal como ocorre com as sociedades humanas, nas quais há fluidez dos fenômenos sociais, a dificuldade em definir categorias e determinar padrões de observação devido ao grande número de variáveis envolvidas, à subjetividade do pesquisador e ao caráter multifacetado dos fenômenos observados, os primatólogos dedicados ao estudo da vida coletiva dos chimpanzés enfrentam dificuldades tais como os modos diversos pelos quais os observadores registram a participação dos chimpanzés nos grupos, as diferentes definições utilizadas para sexo e idade e as análises dos padrões de associação utilizados para fazer inferências acerca da existência de vínculos e afinidades (Mitani; Watts; Muller, 2002, p. 11).

As saídas adotadas pelos pesquisadores têm sido a elaboração de índices de associação e a adoção de técnicas randômicas para analisar as associações entre chimpanzés. Ainda assim, por exemplo, os dados levantados sobre o grande grupo de chimpanzés de Ngogo apontam para o fato de que fêmeas que não estão no estro realizam mais associações grupais do que as esperadas pelos índices, configurando variações no padrão e preocupando os primatólogos (Mitani; Watts; Muller, 2002, p. 11).

Uma pergunta adequada a se fazer diante desse tipo de impasse é: uma reflexão profunda sobre das relações entre humanos e suas consequências (Lestel, 2003) sobre, por exemplo, os resultados das pesquisas poderia revelar algo de relevante? A antropomorfização do comportamento dos animais estudados colabora com a compreensão do que se passa, atrapalha ou é inevitável, dado que o ponto de vista humano é indissociável da pesquisa realizada por humanos e, nesse sentido, tal debate é tautológico?

Em outro sentido, mas ainda no âmbito dos questionamentos que a antropologia sociocultural pode fazer aos incríveis resultados de pesquisa primatológica realizada nas últimas décadas, deve-se retomar a discussão sobre as "culturas de chimpanzés". Diferentemente do que ocorre entre os primatólogos que aceitam a proposição da existência de "culturas de chimpanzés" cuja concepção não considera a existência de capacidade simbólica entre os 
chimpanzés como um fator determinante para a existência de cultura tal como é defendido pela antropologia sociocultural (Rapchan, 2005; Rapchan; Neves, 2005), ou associa a existência de comunicação entre chimpanzés como um indício convincente de capacidade simbólica (King, 2004).

O princípio segundo o qual somos todos primatas e, por isso, possuímos mais semelhanças do que diferenças ${ }^{1}$ tem adquirido cada vez mais consistência e mais sentido à medida que avançam as pesquisas. Mais do que isso, a negação da separação entre corpo e "alma", que adquiriu fundamentos com o materialismo de Darwin, prova-se válida. Assim, acumulam-se elementos que comprovam que os humanos não apenas se parecem com seus parentes mais próximos mas comportam-se de modo semelhante a eles em relação a muitos aspectos, confirmando que a maior parte das diferenças existentes entre nós é de grau.

É justamente na convergência entre os fenômenos relativos a "cultura", "sociabilidade", "cognição" e "capacidade simbólica" que se dá o mais importante debate atual acerca do que podemos aprender e descobrir sobre a condição humana. Explicando melhor, de um lado, existe o reconhecimento da existência de várias espécies de animais sociais, que está associado a um entendimento de que formas de inteligência semelhantes à humana são encontráveis em espécies que têm com os humanos maior proximidade genética e resultam em comportamentos coletivos de complexidade semelhante (Dunbar, 1997). De outro, os comportamentos relacionados à vida em grupo dependem, não se sabe em que grau, da dinâmica do próprio grupo. De qualquer modo, não são definidos exclusivamente por herança. Por fim, a variabilidade de comportamentos grupais já registrada aponta para certas características consideradas exclusivas das culturas humanas. Daí, se o debate envereda para concepções de cultura, será preciso considerar o problema da capacidade simbólica. Grandes primatas, por exemplo, têm sido percebidos como seres que avaliam e analisam possibilidades para escolher as alternativas mais adequadas dentre as opções que possuem (De Waal, 2007), aprendem por imitação (Tomasello, 2003), que é, aliás, a primeira conduta cognitiva das crianças humanas (De Waal, 2007), e podem ensinar o que aprenderam aos mais jovens (Fouts; Mills, 1998). Em outras palavras, trata-se de seres inteligentes, cujo

1 Frans de Waal, em entrevista à revista eletrônica Com Ciência (Cantarino, 2006).

Horizontes Antropológicos, Porto Alegre, ano 16, n. 33, p. 227-266, jan./jun. 2010 
aprendizado está diretamente relacionado à vida em grupo e que aprendem por experiência própria ou pelo repasse de experiências de outros.

A identificação de fenômenos no comportamento animal, notadamente entre os grandes símios, nomeados como "sociedade", "tradição" e "cultura" levou alguns pesquisadores a estudar as capacidades cognitivas de animais não humanos (Tomasello, 2003), pois comportamentos mais complexos, e que implicam escolhas entre as variáveis comportamentais possíveis, são indícios de altos graus de inteligência associados à ampla capacidade de aprendizado, e este último diz respeito, diretamente, à vida em grupo. Enquanto isso, outros estudiosos dedicaram-se a observar o que eles passaram a chamar de "cultura" animal. Contudo, os críticos à aplicação da ideia de cultura aos fenômenos que ocorrem na esfera do comportamento de animais não humanos derivam seus argumentos de um princípio essencial da concepção antropológica de cultura, ou seja, para identificar a existência de cultura entre seres não humanos é preciso comprovar a existência de capacidade simbólica (Galef, 1992; Rapchan; Neves, 2005).

Assim, enquanto a centralidade da capacidade simbólica parece ser um dos poucos e únicos consensos a que chegaram os antropólogos sociais e culturais acerca da capacidade de um ser produzir e reproduzir cultura (Geertz, 1978; Kuper, 1999; Rapchan; Neves, 2005), ironicamente, é esse o ponto de discórdia entre os que afirmam a existência de cultura entre animais não humanos e os que, também por uma via evolutiva, a questionam. Retomando o problema, tanto "cognição" quanto "cultura" são tidos por todos os pesquisadores das áreas fundadas nas biociências como fenômenos decorrentes de processos evolutivos, contudo, eles correspondem a aspectos não físicos da evolução e, portanto, analisar suas evidências e compreendê-los é um desfio, em termos de pesquisa, e uma empreitada intelectual bastante complexa e tortuosa.

No entanto, ao mesmo tempo em que parece haver algum consenso em torno do princípio de que a capacidade cognitiva, identificada em outros grandes símios, por exemplo, evoluiu gradativamente (Tomasello, 2003), o mesmo não ocorre em relação à capacidade simbólica. Para muitos primatólogos, é possível identificar a existência de capacidade simbólica entre chimpanzés, manifesta, por exemplo, nos comportamentos associados à comunicação (King, 2004); em contrapartida, para a maioria dos paleoantropólogos, a capacidade simbólica, quando surgiu no processo evolutivo, inundou todos os 
aspectos da vida coletiva e mental, promoveu o surgimento da arte, dos mitos e dos rituais, da ciência e das metáforas (Mithen, 2002). Tal surgimento seria, portanto, resultado de um "salto" evolutivo, termo proposto por Gould e Lewontin para alguns casos e aceito hoje pela maior parte dos especialistas em evolução. De fato, segundo Mithen (2002), a capacidade simbólica é um fenômeno muito recente até na história humana e, portanto, não se manifestou, mesmo entre nossos antepassados hominíneos, até aproximadamente $10 \mathrm{mil}$ anos antes do presente (A.P.).

Segundo Mithen (2002), entre 100 mil e 30 mil anos A.P. ocorreram fenômenos que estão ligados a uma mudança crucial na evolução da mente moderna: a passagem da condição de "canivete suíço" para a "fluidez cognitiva", essa última associada a capacidades tais como a possibilidade de realizar desenhos complexos, produzir arte, ter crenças em ideologias religiosas, cultivar plantas e domesticar animais. Segundo evidências, tudo isso está diretamente relacionado à associação entre a "inteligência naturalista" e a "inteligência social". Tal ocorrência permitiu a manipulação de objetos físicos animados ou inanimados (supondo-se que eles não têm emoções) e a aplicação desse princípio às pessoas, ou seja, surgiram simultaneamente tanto a capacidade de desenvolver o pensamento antropomórfico e totêmico quanto o pensamento etnocêntrico e racista.

De acordo com as análises dedicadas por Mithen (2002) a um arsenal de pesquisas desenvolvidas em primatologia, paleoantropologia, antropologia biológica e disciplinas afins, desde nosso mais antigo antepassado primata que originou a evolução do que chamamos de "mente humana" entre, aproximadamente, 65 a 55 bilhões de anos atrás, deu-se um longo e intrincado processo, profundamente dependente da concomitante capacidade e necessidade de vida grupal, que resultou em dois momentos críticos.

Entre 500 mil e 200 mil anos A.P. um novo, e decisivo, surto de expansão cerebral ocorreu. As evidências desse processo são: a ampliação dos grupos sociais e a concomitante necessidade de defender-se de outros humanos, o surgimento da linguagem como oportunidade de transferir informação à mente (própria ou de outro); ao mesmo tempo, a linguagem transforma seu caráter de social para geral e a consciência tornou-se gerenciadora de um banco de dados com informações sobre todos os domínios do comportamento. Tem-se, naquele momento, os indícios da origem da capacidade simbólica, talvez o único fator relacionado à singularidade humana. 
Entre 100 mil e 10 mil anos A.P. pesquisadores encontraram elementos que apontam para o surgimento de uma fluidez cognitiva crescente e para a emergência das capacidades que, segundo Mithen (2002), estão nas origens cognitivas da ciência, tais como a habilidade para gerar e testar hipóteses, a capacidade de desenvolver e usar ferramentas ou objetos para testar hipóteses específicas e a possibilidade de usar metáforas e analogias como "ferramentas do pensamento" (Dennet, 1997).

\section{A primatologia e suas questões para a antropologia sociocultural (e vice-versa)}

A carência de reflexões contemporâneas sobre questões postas pela antropologia para a biologia e vice-versa, bem como as implicações metodológicas e teóricas nas fronteiras entre ambas, tem sido assinalada por antropólogos sociais como Adam Kuper (1994, p. viii), Tim Ingold (1996) e Dan Sperber (1996) em favor de se reunir esforços para abordar o problema. Kuper avalia se somos todos darwinistas, inclusive os antropólogos, e propõe uma reflexão sobre o assunto bem como o diálogo da antropologia com as ideias e resultados atuais das pesquisas pautadas nas biociências, considerando seu impacto e as contribuições para conhecimento que isso pode trazer. Ingold (1996, p. 112-113), por sua vez, questiona se mesmo os antropólogos, em seu exercício intelectual, têm de, necessariamente, aceitar um paradigma dicotômico e optar pela "animalidade" ou pela "humanidade", por "um mundo" ou "vários mundos", pela "natureza" ou pela "cultura", pelo "dado" ou pelo "constructo" ou se nossa cognição existe a partir de uma orientação que produz seres humanos não a partir de dicotomias mas de uma matriz relacional, e escolhe a segunda alternativa para propor reflexões sobre vários ângulos possíveis para as relações entre humanos e não humanos. Dan Sperber (1996) engrossa as fileiras dos que defendem uma integralização conceitual entre diferentes áreas do conhecimento, de modo tal que as afirmações da antropologia venham a dialogar e levar em consideração conceitos e descobertas gerados em outras áreas do conhecimento, e defende uma "naturalização" da antropologia. O que se tem aqui, sem dúvida, é a constituição de um ponto crítico tanto para as ciências sociais e humanas quanto para as, por assim dizer, ciências da vida.

A partir de sua experiência como editor da revista Current Anthropology, entre 1985 e 1993, Adam Kuper percebeu a emergência de inúmeros debates 
no campo da antropologia que buscavam associações entre a história das espécies e a diversidade cultural humana e posicionou-se, naquele espaço antropológico interdisciplinar, como um etnógrafo da antropologia (Kuper, 1994, p. viii), para pensar aquele processo. Ao procurar material que apresentasse uma revisão sobre o "estado da arte" naquele assunto, percebeu que existiam poucos bons trabalhos em campos específicos, algumas sínteses modernas e "profetas" anunciando serem os donos da verdade, segundo ele, senhores da "Big Idea"(Kuper, 1994, p. viii), em ambos os lados. Tal constatação o fez produzir uma reflexão sobre o assunto, que recebeu o nome de The chosen primate (Kuper, 1994).

No livro Kuper (1994, p. 11) defende o avanço e aprofundamento do diálogo entre a antropologia e a biologia, considerando a probabilidade de que as pesquisas em genética possam revelar algo sobre as raízes do comportamento humano. Segundo ele, talvez até agentes e processos da evolução cultural possam ser decodificados e a genética possa vir a reescrever todas as ciências humanas (Kuper,1994, p. 11). No entanto, adverte o autor, os objetos culturais e os traços relativos à cultura estão sempre prontos a serem incorporados ou deixados e são extremamente variáveis entre populações para serem transmitidos, tal como se manifestam, pela via da herança genética (Kuper, 1994, p. 11). Assim, defende o autor, é preciso lidar com o fato de que somos um produto de uma dupla herança - a "genética" e a "adquirida e repassada" - e uma não pode determinar a outra em sentido restrito (Kuper, 1994, p. 11).

A "dupla herança", a ser enfrentada e discutida, ou como prefere Ingold (1996), a necessidade de abandonar a adesão essencialista a um dos lados dos já mencionados "duplos paradigmas", somada às questões postas por Cavalli-Sforza (2001) e Corbey; Theunissen (1995) acerca da exigência de uma abordagem multidisciplinar sobre as questões relacionadas à dualidade classicamente denominada "natureza/cultura" não apontam para um esvaziamento das ciências sociais, nem para uma guerra de "culturas", como tem anunciado o primatólogo William McGrew (2004), na qual cada disciplina deva alinhar-se tomando outras como ameaças mortais para sua reprodução, mas, pelo contrário, são indicativos da indiscutível e indispensável contribuição que a antropologia sociocultural e as outras disciplinas de seu grupo podem trazer a esse debate.

Desde aproximadamente 1960, década que é marco da publicação dos primeiros resultados de estudos sobre o comportamento de chimpanzés em 
seus habitats africanos, amparados em coleta de dados e observações resultantes de longos e continuados períodos de permanência no campo, até o momento, informações cada vez mais surpreendentes sobre o comportamento de chimpanzés têm vindo à tona pelas mãos de primatólogos. Parece ir longe a reação de espanto de Louis Leakey diante dos relatos de Jane Goodall (1991) sobre uso de ferramentas, quando ele teria afirmado algo como: "Se você estiver certa, ou alteramos nossa noção de ferramentas ou alteramos o entendimento que temos sobre o que é um ser humano."

Desde então, períodos de campo têm se estendido de, no mínimo, nove meses a duas, três ou quatro décadas, com a formação de equipes permanentes, cujo trabalho é interrompido quase que apenas pela violência e brutalidade decorrentes da trágica instabilidade sociopolítica de muitas das regiões africanas habitadas por chimpanzés e seres humanos. No processo muito material têm vindo a público. Jane Goodall está no Parque Nacional de Gombe, na Tanzânia, desde 1960, Toshisada Nishida faz pesquisa no Paque Nacional das Montanhas Mahale desde 1965 e Christophe e Hedwige Boesch trabalham na floresta de Taï, na Costa do Marfim, desde 1976. Os quatro foram os precursores dos três projetos de pesquisa sobre comportamento chimpanzé que acumulam o maior tempo de observação contínua sobre indivíduos chimpanzés conhecidos (Goodall 2001, p. xv-xvii).

Às pesquisas feitas em habitats originais africanos somaram-se pesquisas feitas sobre comportamento em ambientes humanizados nos quais chimpanzés e bonobos têm passado a maior parte de sua vida, como centros de pesquisa e mesmo alguns zôos (Boehm, 2001; Fouts; Mills, 1998; De Waal, 2000, Jahme, 2001, Parker; Gibson, 1994; Parr; De Waal, 1999, Rumbaugh; Savage-Rumbaugh; Sevcick, 2001, Tomasello; Call, 1997). Há até uma década, os pesquisadores de ambos os grupos dividiam-se em função do tipo de observação que cada situação proporcionava: o meio original em florestas africanas, habitats artificiais ou alterados, como os parques e santuários, e ambientes controlados por humanos, como os centros de pesquisa e laboratórios, que observam comportamentos a partir de indução, simulação, estímulo, etc. Segundo Goodall (2001, p. xvii-xviii), recentemente, têm-se criado um consenso pautado no princípio de que essa diversidade de pesquisas pode ampliar a compreensão sobre os chimpanzés. Desde então, tem-se buscado aproximações, realizado trabalhos conjuntos e comparado seus resultados de pesquisa. 
Os trabalhos em primatologia dirigidos ao estudo do comportamento têm, nas últimas décadas, observado a existência de mecanismos de aprendizado, inventividade, variabilidade de comportamento, transmissão e reprodução de condutas incluindo não apenas o meio ecológico mas outros animais da mesma e de outras espécies. Identificam e analisam interações pelas chaves de aliança e conflito, status e vantagens adquiridas, dissimulação diante dos mais fortes, reações diante do inesperado, repasse do conhecimento obtido, que alguns chamam "tradição" (Nishida, 1987). O que sobressai da leitura desse material é que a dimensão biológica dos chimpanzés observados não é concebida como um determinante cego e fixo, mas como uma herança que oferece as possibilidades de desenvolvimento social de habilidades cognitivas e acúmulo de experiências.

Enfim, os pesquisadores supramencionados, e outros não citados, partem da observação e registro do comportamento dos chimpanzés, analisam esse material considerando a centralidade e o papel do que se costuma chamar de "adquirido", concebem as relações entre herança genética e experiência do indivíduo com o grupo e o meio como um processo dinâmico, interativo e não determinístico. Ou seja, esses estudiosos operam de um modo tal que, em conjunto, pode-se afirmar sobre eles que características genéticas e experiência de vida possuem a mesma importância, relacionam-se dinamicamente.

Em contrapartida, se os aspectos pertinentes à constituição físico-químico-biológica dos seres nunca é descartada pelos primatólogos, é importante avaliar como se dá sua participação na constituição desse conhecimento. $\mathrm{O}$ "inato" pode assumir papéis mais determinantes ou mais relacionais na definição dos seres vivos, de acordo com o caráter da discussão. O pressuposto fundado, grosso modo, em concepções pautadas na "materialidade" de tudo o que é relacionado à vida (Tooby; Cosmides, 1995) multiplica-se em várias hipóteses e caminhos de pesquisa, mas parece insinuar-se mais explicitamente nos trabalhos de cunho teórico e subordinar-se mais aos dados quando está referido a uma pesquisa. Nesse sentido, as influências de Darwin desdobraramse em mais de uma perspectiva.

Sob esse aspecto, a proposta de Kuper consiste em lembrar que se é de consenso o ponto de vista darwiniano, segundo o qual a seleção natural atua sobre o organismo, por outro lado a herança genética sozinha não é capaz de explicar a performance dos seres ao longo de sua existência, particularmente ou seres humanos. Ou seja, para Kuper, uma coisa é avançar o 
debate sobre as relações biologia/cultura, outra é optar exclusivamente pela determinação genética em detrimento do que é aprendido pela vivência. Segundo Kuper (1994, p. 15), a cultura interfere no processo de seleção natural. Cavalli-Sforza (2001, p. viii), por sua vez, afirma que as inovações tecnológicas e a produção cultural, num sentido amplo, têm afetado profundamente a evolução genética humana (Cavalli-Sforza, 2001, p. 5-7).

Um dos exemplos disso, segundo Cavalli-Sforza, seriam resultados de teorias desenvolvidas por matemáticos segundo os quais a distância genética entre duas populações aumenta na proporção direta de seu distanciamento geográfico. A explicação de Cavalli-Sforza para isso reside na prática da troca de esposas - a exogamia -, artefato cultural relacionado ao tabu do incesto, à instituição das relações de parentesco, orientado a partir de relações complexas com a alteridade, uma das questões que marcou a profunda influência de Lévi-Strauss (1988) na antropologia e que, segundo Cavalli-Sforza (2001, p. 23), afeta diretamente a migração humana. Em contrapartida, quando se toma a genética de um ser humano pertencente a determinado grupo, pode-se descobrir que ele possui grandes semelhanças genéticas com outros dois sujeitos tomados aleatoriamente, pertencentes a outros grupos, em função direta do grau de partilha de ancestrais comuns entre eles (Cavalli-Sforza, 2001, p. 31), o que aponta para a pequena variabilidade genética humana e, consequentemente, para a enorme semelhança dos humanos no tange a esse patrimônio, anulando inclusive a idéia de que existam "raças" humanas.

O movimento que se observa é que, à medida que as pesquisas genéticas avançam na direção de demonstrar a grande semelhança entre o DNA humano e chimpanzé (Goodman, 1999) e pesquisas em paleoantropologia indicam que aspectos ecológicos e anatômicos reforçam os indícios acerca da origem dos chimpanzés e dos primeiros hominídeos a partir de um ancestral comum (Wrangham; Peterson, 2004), pesquisadores dedicados ao estudo do comportamento de chimpanzés levantam dados e questões que procuram sustentar a existência de uma continuidade entre primatas superiores e humanos, não apenas no plano do que é anatômico ou fisiológico, mas também com relação às capacidades herdadas em relação àquilo que é aprendido, adquirido por experiência, inventado e ensinado aos outros. Como referido anteriormente, talvez nossa capacidade simbólica seja a única exceção e, em sendo assim, a antropologia sociocultural tem muito a aprender com as biociências e, especialmente, com a primatologia e também, sem dúvida, muito a ensinar. 


\section{Referências}

ARCADI, A. C.; WRANGHAM, R. W. Infanticide in chimpanzees: review of cases and a new within-group observation from de kanyawara study group in Kibale National Park. Primates, v. 40, n. 2, p. 337-351, 1999.

ARNOLD, K.; WHITEN, A. Post-conflict of wild chimpanzees (pan troglodytes schweinfurtii) in the Bundongo Forest, Uganda. Behaviour, n. 138, p. 649-90, 2001.

ASQUITH, P. J. Of monkeys and men: cultural views in Japan and the West. In: CORBEY, R.; THEUNISSEN, B. (Ed.). Ape, man, apeman: changing views since 1600. Leiden: Leiden University, 1995. p. 309-326.

BAKER, K. C.; SMUTS, B. S. Social relationships of female chimpanzees: diversity between captive social groups. In: WRANGHAM, R. W. et. al. (Ed.). Chimpanzee cultures. Chicago: Harvard University Press/Chicago Academy of Sciences, 2001. p. 227-242.

BAKER, K. C. et. al. Injury risks among chimpanzees in three housing conditions. American Journal of Primatology, v. 51, n. 3, p. 161-75, 2000.

BARKOW, J. H. et al. The adapted mind. New York: Oxford University Press, 1995.

BENEDICT, R. O crisântemo e a espada, São Paulo: Perspectiva, 1988.

BENEDICT, R. Padrões de cultura, Lisboa: Edição Livros do Brasil, [s.d.].

BLANC, M. Os herdeiros de Darwin. São Paulo: Página Aberta, 1975.

BOAS, F. Race, language, culture. New York: The MacMillan Company, 1940.

BOESCH, C.; BOESCH, H. Tool use and tool making in wild chimpanzees. Folia Primatologica, n. 54, p. 86-99, 1990.

BOESCH, C.; TOMASELLO, M. Chimpanzee and human cultures. Current Anthropology, v. 39, n. 5, p. 591-614, 1998. 
BOEHM, C. Pacifying interventions at Arnhem Zoo and Gombe. In: WRANGHAM, R. W. et. al. (Ed.). Chimpanzee cultures. Chicago: Harvard University Press/Chicago Academy of Sciences, 2001. p. 211-226.

BONNER, J. T. A evolução da cultura nos animais. Rio de Janeiro: Zahar, 1983.

BROSNAN, S. F.; DE WAAL, F. B. M. Monkeys reject unequal pay. Nature, n. 425, p. 297-99, 2003.

BROWNE, J. A Origem das Espécies de Darwin: uma biografia. Rio de Janeiro: Zahar, 2007.

CANTARINO, C. Entrevistas: Frans de Waal. Com Ciência, n. 80, 19 set. 2006. Disponível em: $<$ http://www.comciencia.br/comciencia/?section=8\&ed icao $=17 \&$ tipo $=$ entrevista $>$. Acesso em: 1 out. 2009.

CARVALHO, J. J. A antropologia e o niilismo filosófico contemporâneo. Brasília: UnB, 1988. (Série Antropologia, n. 71).

CAVALLI-SFORZA, L. L. Genes, peoples and languages. London: Penguin Books, 2001.

CHENEY, D. L.; SEYFARTH, R. M. How monkeys see the world. Chicago: University of Chicago Press, 1990.

CORBEY, R.; THEUNISSEN, B. (Ed.). Ape, man, apeman: changing views since 1600. Leiden: Leiden University, 1995.

DAMÁSIO, A. O mistério da consciência. São Paulo: Companhia das Letras, 2000.

DENNET, D. Kinds of minds: towards an understanding of consciousness. New York: Basic Books, 1997.

DE WAAL, F. B. M. Chimpanzee's adaptative potencial: a comparison of social life under captive and wild conditions. In: WRANGHAM, R. W. et. al. (Ed.). Chimpanzee cultures. Chicago: Harvard University Press/Chicago Academy of Sciences, 2001a. p. 243-262. 
DE WAAL, F. B. M. Overview - culture and cognition. In: WRANGHAM, R. W. et. al. (Ed.). Chimpanzee cultures. Chicago: Harvard University Press/ Chicago Academy of Sciences, 2001b. p. 263-266.

DE WAAL, F. B. M. Chimpanzee Politics: Power and Sex Among Apes, Baltimore: The Johns Hopkins University Press, 2000.

DE WAAL, F. Eu, primata: porque somos como somos, São Paulo: Cia. das Letras, 2007.

DESCOLA, P. In the society of nature. Harvard: Cambridge University Press, 1994.

DUMONT, L. O individualismo. Rio de Janeiro: Rocco, 1993.

DUNBAR, R. Grooming, gossip and the evolution of language. Edimburg: Word Power Books, 1997.

DUKELOW, R. W. Invited editorial: reflections on a century of primatology. American Journal of Primatology, n. 49, p. 129-132, 1999.

EVANS-PRITCHARD, E. E. Os nuer. São Paulo: Perspectiva, 1978.

FOUTS, O.; MILLS, S. T. O parente mais próximo: o que os chimpanzés me ensinaram sobre quem somos. Rio de Janeiro, Objetiva, 1998.

GALEF, B. The question of animal culture. Human Nature, n. 3, p. 157-178, 1992.

GEERTZ, C. A interpretação das culturas. Rio de Janeiro: Zahar, 1978.

GIBSON, K. R.; INGOLD, T. (Ed.). Tools, language and cognition in human evolution. London: Cambridge, 1995.

GOLDMAN, M.; LIMA, T. S. Como se faz um Grande Divisor?. In: GOLDMAN, M. (Ed.). Alguma antropologia. Rio de Janeiro: Relume Dumará, 1999. p. 38-45.

GOODALL, J. The chimpanzees of Gombe. Cambridge: Belknap Press, 1986.

GOODALL, J. Uma janela para a vida: 30 anos com os chimpanzés da Tanzânia. Rio de Janeiro: Zahar, 1991. 
GOODALL, J. In the shadow of man. New York: Mariner Books, 2000.

GOODALL, J. Foreword. In: WRANGHAM, R. W. et. al. (Ed.). Chimpanzee cultures. Chicago: Harvard University Press/Chicago Academy of Sciences, 2001. p. xv-xxi.

GOODMAN, J. The genomic record of humankind's evolutionary roots. American Journal of Human Genetics, n. 64, p. 32-39, 1999.

HARAWAY, D. Primate visions: gender, race, and nature in the world of modern science. London: Routledge, 1989.

HARAWAY, D. simians, cyborgs and women: the reinvention of nature, New York: Routledge, 1991.

HARRIS, M. Vacas, cerdos, guerras y brujas. Madrid: Alianza Editorial, 2008.

HELTNE, P. G. Preface. In: WRANGHAM, R. W. et. al. (Ed.). Chimpanzee cultures. Chicago: Harvard University Press/Chicago Academy of Sciences, 2001. p. xi-xiii.

HENRICH, J.; McELREATH, R. The evolution of cultural evolution. Evolutionary Anthropology, n. 12, p. 123-135, 2003.

HOLTON, G.; ELKANA, Y. (Ed.). Albert Einstein: historical and cultural perspectives. New York: Dover Science, 1997.

HOOFF, J. V. Understanding chimpanzee understanding. In: WRANGHAM, R. W. et. al. (Ed.). Chimpanzee cultures. Chicago: Harvard University Press/ Chicago Academy of Sciences, 2001. p. 267-284.

HRDY, S. B. Mãe Natureza. Rio de Janeiro: Campus, 2001.

INGOLD, T. (Ed.). Key debates in anthropology. London: Routledge, 1996.

JAHME, C. Beauty and the beasts: woman, ape and evolution. London: Virago, 2001.

JOULIAN, F. Comparing chimpanzee and early hominid techniques: some contributions to cultural and cognitive questions. In: MELLARS, P. A.; GIBSON, K. A. (Ed.). Chimpanzee cultures. Cambridge: McDonald Institute for Archaeological Research, 1996. p. 173-189. 
KING, B. J. The dynamic dance: nonvocal communication in African great apes. Cambridge: Harvard University Press, 2004.

KÖHLER, W. The mentality of apes. London: Routledge. 1999.

KRÖEBER, A. L. The nature of culture. Chicago: The University of Chicago Press, 1952.

KUPER, A. The chosen primate. Cambridge: Harvard University Press, 1994.

KUPER, A. The invention of primitive society: transformations of an illusion. London: Routledge, 1996.

KUPER, A. Culture: the anthropologists' account. Cambridge: Harvard University Press, 1999.

KUPER, A. If memes are the answer, what is the question?. In: AUNGER, R. (Ed.). Darwinising culture: the status of memetics as a science. Oxford: Oxford University Press, 2000. p. 175-188.

KUPER, A.; KUPER, J. The social sciences encyclopedia. New York: Routledge, 2003.

LATOUR, B. Jamais fomos modernos: ensaios de antropologia simétrica. Rio de Janeiro: Relume Dumará, 1991.

LESTEL, D. Les origines animales de la culture. Paris: Flamarion, 2003.

LESTEL, D. L'animal singulier. Paris: Seuil, 2004.

LÉVI-STRAUSS, C. O totemismo hoje. Lisboa: Edições 70, 1986.

LÉVI-STRAUSS, C. Las estructuras elementales del parentesco. Barcelona: Paidós, 1988.

LÉVI-STRAUSS, C. Antropologia estrutural. Rio de Janeiro: Tempo Brasileiro, 1989a.

LÉVI-STRAUSS, C. O pensamento selvagem. Campinas: Papirus, $1989 \mathrm{~b}$.

LÉVI-STRAUSS, C. Antropologia estrutural dois. Rio de Janeiro: Tempo Brasileiro, 1993. 
LEWIS, H. S. Boas, Darwin, science, and anthropology. Current Anthropology, v. 42, n. 3, p. 38-406, 2001.

MALINOWSKI, B.Os argonautas do Pacifico ocidental. São Paulo: Abril, 1978. (Coleção Os Pensadores).

MARCUS, G. Ethnography in/of the world system: the emergence of multisited ethnography. The Annual Review of Anthropology, n. 24, p. 95-117, 1995.

MASON, W.A.; MENDOZA, S. P. (Ed.). Primate social conflict. Albany: State University of New York Press, 1993.

MATSUZAWA, M. Primate foundations of human intelligence: a view of tool use in nonhuman primates and fossil hominids. In: MATSUZAWA, M (Ed.). Primate origins of human cognition and behaviour. Tokio: Springer-Verlag, 2001. p. 3-25.

MAUSS. M. O ensaio sobre a dádiva. In: MAUSS, M. Sociologia e antropologia. São Paulo: EPU; Edusp, 1974. p. 37-184.

MAUSS, M. Manual of ethnology. New York: Berghahn Books, 2007.

McGREW, W. C. Chimpanzee material culture: implications for human evolution. Cambridge: Cambridge University Press, 1996.

McGREW, W. C. The cultured chimpanzee: reflections on cultural primatology. Cambridge: Cambridge University Press, 2004.

MEAD, M. Sexo e temperamento. São Paulo: Perspectiva, 1969.

MITANI, J. C.; MERRIWETHER, D. A.; ZHANG, C. Male affiliation, cooperation and kinship in wild chimpanzees. Animal Behavior, n. 59, p.885$893,2000$.

MITANI, J. C.; WATTS, D. P.; MULLER, M. N. Recent development in the study of wild chimpanzee behavior. Evolutionary Anthropology, n. 11, p. 9-25, 2002.

MITCHELL, R. W.; HAMM, M. The interpretation of animal psichology: anthropomorphism or behavior reading? Behavior, n. 134, p.173-204, 1997. 
MITHEN, S. A pré-história da mente. São Paulo: Unesp, 2002.

NEVES, W. E no princípio... era o macaco! Estudos Avançados, v. 20, n. 58, p. 249-285, 2006.

NISHIDA, T. Local traditions and cultural transmission. In: SMUTS, B. B. et al. Primate societies. Chicago: University of Chicago Press, 1987. p. 165-177.

NISHIDA, T.; OHIGASHI, H.; KOSHIMIZU, K. Tastes of chimpanzee plant foods. Current Anthropology, Chicago, v. 41, n. 3, p. 431-438, 2000.

OLIVEIRA, R. C. de. Sobre o pensamento antropológico. Rio de Janeiro: Biblioteca Tempo Universitário, 1997.

PARKER, S. T.; GIBSON, K. R. 'Language' and intelligence in monkeys and apes. Cambridge: Cambridge University Presses, 1994.

PARR, L.; DE WAAL, F. B. M. Like mother, like son: visual kin recognition. Nature, n. 399, p. 647-648, 1999.

PAVELKA, M. S. M.. Change versus improvement over time and our place in nature. Current Anthropology, Supplement 43, S37-S44, 2002.

PEIRANO, M. A teoria vivida. Rio de Janeiro: Zahar, 2006.

RABINOW, P. Humanism as nihilism: the bracketing of truth and seriousness in American cultural anthropology. In: BELLAH, N. et al. Social science as moral inquiry. New York: Columbia University Press, 1983. p. 52-75.

RAPCHAN, E. S. Relativismo epistêmico, relativismo antropológico: reflexões sobre a produção do pensamento no âmbito das construções da antropologia. Acta Scientiarum, v. 24, n. 1, p. 261-270, 2002.

RAPCHAN, E. S. Chimpanzés possuem cultura? Questões para a antropologia sobre um tema "bom para pensar". Revista de Antropologia, São Paulo, v. 48, n. 1, p. 227-280, 2005.

RAPCHAN, E. S.; NEVES, W. A. Chimpanzés não amam! Em defesa do significado. Revista de Antropologia, São Paulo, v. 48, n. 2, p. 649-698, 2005. 
RICHARDS, P. Local understandings of primates; evolution: some mende beliefs concerning chimpanzees. In: CORBEY, R.; THEUNISSEN, B. (Ed.). Ape, man, apeman: changing views since 1600. Leiden: Leiden University, 1995. p. 265-273.

RUMBAUGH, D. M.; SAVAGE-RUMBAUGH, E. S.; SEVCIK, R. A. Biobehavioral roots of language: a comparative perspective of chimpanzee, child and culture. In: WRANGHAM, R. W. et. al. (Ed.). Chimpanzee cultures. Chicago: Harvard University Press/Chicago Academy of Sciences, 2001. p. 319-334.

SAHLINS, M. Stone Age economics. New York: Taylor; Francis, 2005.

SCHWARCZ, L. M. O espetáculo das raças. São Paulo: Companhia das Letras, 1993.

SPERBER, D. Explaining culture. New York: John Wiley Professional Ed., 1996.

STANFORD, C. B. The social behaviour of chimpanzees and bonobos. Current Anthropology, v. 39, n. 4, p 399-420, 1998.

STRATHERN, M. Parts and wholes: refiguring relationships in a post-plural world. In: KUPER, A. (Ed.). Conceptualizing society. London: Routledge, 1992. p. $75-104$.

STOCKING Jr., G. W. Race, culture and evolution. Chicago: University of Chicago Press, 1982.

TOOBY, J.; COSMIDES, L. The psychological foundations of culture. In: BARKOW, J. et al. (Ed.). The adapted mind. New York: Oxford University Press, 1995. p. 19-136.

TODOROV, T. Nós e os outros: vol. 1. Rio de Janeiro: Zahar, 1993.

TOMASELLO, M. As origens culturais da aquisição do conhecimento. São Paulo: Martins Fontes, 2003.

TOMASELLO, M.; CALL, J. Primate cognition. New York: Oxford University Press, 1997. 
TUTTLE, R. H. On culture and traditional chimpanzees. Current Anthropology, v. 42, n. 3, p. 407-408, 2001.

WAGNER, R. the invention of culture. Chicago: The University of Chicago Press, 1991.

WEINER, J. Tempo, amor e memória: um biólogo notável e sua busca das origens do comportamento. Rio de Janeiro: Rocco, 2001.

WHITEN, A. et al. Cultures in chimpanzees. Nature, n. 399, p. 682-685, 1999.

WOLKER, R. Enlightening apes: eighteenth-century speculation and current experiments on linguistic competence. In: CORBEY, R.; THEUNISSEN, B. (Ed.). Ape, man, apeman: changing views since 1600. Leiden: Leiden University, 1995. p. 87-100.

WRANGHAM, R. W. Overview - ecology, diversity, and culture. In: WRANGHAM, R. W. et. al. (Ed.). Chimpanzee cultures. Chicago: Harvard University Press/Chicago Academy of Sciences, 2001. p. 21-24.

WRANGHAM, R. W. et. al. (Ed.). Chimpanzee cultures. Chicago: Harvard University Press/Chicago Academy of Sciences, 2001.

WRANGHAM, R.; PETERSON, D. Demonic males. Boston: Houghton Mifflin, 2004. 